\section{FATOS MARCANTES NA HISTÓRIA DOS TESTES PSICOLÓGICOS}

\author{
José Aparecido da Silva* \\ Universidade de São Paulo
}

2200 a.C.Os chineses começam a usar testes/ exames no serviço público civil

1862 Wilhelm Wundt usa um pêndulo calibrado para medir a "velocidade do pensamento"

1884 Francis Galton aplica a primeira bateria de teste mental para milhares de pessoa na Exposição Internacional de Saúde

1890 James McKeen Cattel usa o termo "teste mental" para anunciar a agenda de sua Bateria de Testes Galtonianos

1901 Clark Wissler descobre que os testes/ instrumentos criados por Cattell não tinham qualquer correlação com as séries escolares

1904 Charles Spearman propõe que a inteligência consiste de um simples fator geral " $g$ " e de numerosos fatores específicos (s)

1905 Binet e Simon inventam o primeiro teste moderno de inteligência

1914 Stern introduz o termo QI ou quociente de inteligência: a idade mental dividida pela idade cronológica

1916 Lewis Terman faz a revisão da Escala de Binet-Simon e publica a Escala StanfordBinet. Novas revisões aparecem em 1937, 1960 e 1986

1917 Robert Yerkes desenvolve os Testes Army Alpha e Beta usados para testar e avaliar os recrutas norte-americanos durante a primeira Grande Guerra Mundial

1917 Robert Woodworth desenvolve o primeiro teste de personalidade (Personal Data

*Endereço para correspondência: José Aparecido da Silva, Departamento de Psicologia e Educação, Faculdade de Filosofia, Ciências e Letras de Ribeirão Preto, Universidade de São Paulo, Avenida Bandeirantes, 3900 , CEP14040-901.E-mail:jdasilva@ffclrp.usp.br
Sheet).

1921 Publicado o Teste de Rorschach para avaliação da personalidade

1921 A "Psychological Corporation", a primeira editora para publicação de testes psicológicos, foi fundada por Cattell, Thorndike e Woodworth

1927 Publicada a primeira edição do Teste Vocacional de Interesses (Strong Vocational Interest Blank)

1935 Morgan e Murray publicam, na Universidade de Harvard, o Teste de Apercepção Temática

1938 L.L.Thurstone propõe que a inteligência consiste de aproximadamente sete grupos de fatores conhecidos como habilidades mentais primárias

1938 Raven publica o Teste das Matrices Progressivas, um teste de inteligência nãoverbal suposto medir o Fator " $\mathrm{g}$ ", concebido por Spearman

1939 Publicada a Escala de Weschler-Bellevue de Inteligência (WAIS). A Escala revisada foi publicada em 1955 (WAIS), 1981 (WAIS-R) e 1997 (WAIS-III)

1942 Publicado o Inventário Multifásico de Personalidade (MMPI)

1949 Publicada a Escala Wechsler de Inteligência Infantil (WISC). Novas revisões foram publicadas em 1974 (WISC-R), 1989, 1991 e 1997 (WISC-III)

1951 Lee Cronbach introduz o coeficiente Alpha como um índice de fidedignidade (consistência interna) para testes e escalas

1963 Raymond Cattell propõe a Teoria da Inteligência Fluída e Cristalizada

1969 Arthur Jensen propõe, na revista Harvard Educational Review, a hipótese genética das diferenças em QI entre brancos e afroamericanos

1985 A Associação Americana de Psicologia (APA), juntamente com outras sociedades 
profissionais e científicas de psicologia, publicam o influente "Standards for

Educational and Psychological Testing

1994 Herrnstein e Murray reativam o debate entre raça e hereditariedade do QI com a publicação do famoso livro "The Bell Curve"

1996 O relatório da Força Tarefa constituída pela American Psychological Association (APA) é publicado na revista American Psychologist em função do debate e das discussões levantadas a partir da publicação do livro The Bell Curve sobre o significado dos testes e a natureza da inteligência.

1997 Robert Sternberg organiza um número especial da revista American Psychologist. especialmente dedicado à inteligência e aprendizagem por toda a vida

2001 Stephen Petrill e Ian Deary organizam um número especial da revista Intelligence, especialmente dedicado à análise da correlação entre tempo de inspeção e diferenças na inteligência psicométrica 